\title{
Contemporaneidade e literatura: reflexões sobre uma possível literatura do contemporâneo
}

\author{
Jefferson de Morais Lima* \\ Universidade do Estado do Rio de Janeiro \\ Rio de Janeiro, Brasil \\ Recebido em: 30/04/2019 \\ Aceito em: 06/o8/2019
}

Pensar é estar doente dos olhos.

Fernando Pessoa, O guardador de Rebanhos, 8 de março de 1914.

Resumo: Este artigo analisa a ideia de contemporaneidade formulada por Giorgio Agamben, com base em filósofos que influenciaram o pensamento do filósofo italiano. Com a contribuição crítica de Walter Benjamin, reflete sobre Charles Baudelaire como um artista contemporâneo e propõe reflexões sobre quais seriam os traços de uma possível literatura do contemporâneo, com o suporte teórico de Theodor Adorno.

Palavras-chave: Literatura. Contemporaneidade. Literatura do contemporâneo.

\begin{abstract}
This article analyzes the idea of contemporaneity formulated by Giorgio Agamben, based on philosophers that influenced the Italian philosopher's thinking. With the critical contribuition of Walter Benjamin, it reflects on Charles Baudelaire as a contemporary artist and proposes reflections about what would be the traces of a possible literature of the contemporary, with the theoretical support of Theodor Adorno.
\end{abstract}

Keywords: Literature. Contemporaneity. Literature of the contemporary.

Resúmen: Este artículo analiza la idea de contemporaneidad formulada por Giorgio Agamben, basado en filósofos que influenciaron el pensamiento del filósofo italiano. Con la contribución crítica de Walter Benjamin, reflexiona sobre Charles Baudelaire como artista contemporáneo y propone reflexiones sobre cuáles serían las marcas de una posible literatura del contemporáneo, con el apoyo teórico de Theodor Adorno.

Palabras clave: Literatura. Contemporaneidad. Literatura del contemporáneo. 


\section{Introdução}

Neste artigo, objetivamos refletir sobre os fatores teórico-epistemológicos que cooperam para a criação do que entendemos como uma possível literatura do contemporâneo, para, dessa forma, compreendermos melhor quais seriam as suas marcas e a razão pela qual utilizamos esse termo.

De imediato, é necessário esclarecermos que a ideia de contemporaneidade chega a nós por meio da contribuição teórica de Giorgio Agamben, o qual apresenta para essa palavra uma concepção completamente diferente da usual. Se, no seu uso corrente, esse termo se relaciona a algo ou alguém que se restringe aos tempos atuais ou a um período histórico cujo início é demarcado pelo final do século das luzes, em Agamben ganha outra significação, que diferente bastante das frequentemente registradas pela maior parte dos dicionários.

Sob influência de Barthes - para quem “o contemporâneo é o intempestivo"” (BARTHES apud AGAMBEN, 2009, p. 58) - e Nietzsche, que entre 1873 e 1876 publicara as suas Considerações intempestivas, no ensaio O que é o contemporâneo?, Agamben defende que o verdadeiro contemporâneo é aquele que não coincide perfeitamente com o seu próprio tempo e nem se adéqua às suas pretensões, constituindo-se desse modo como inatual, um ser deslocado e anacrônico. De acordo com o filósofo italiano, é precisamente por conta desse deslocamento e desse anacronismo que o verdadeiro contemporâneo é "capaz, mais do que os outros, de perceber e apreender o seu tempo" (AGAMBEN, 2009, p. 59). Sob essa perspectiva, a contemporaneidade é vista como "uma singular relação com o próprio tempo, que adere a este e, ao mesmo tempo, dele toma distâncias" (AGAMBEN, 2009, p. 59).

O contemporâneo, graças a essa distância, é capaz de observar não apenas o seu tempo, mas todos os outros, percebendo a existência de uma eterna mistura de eras. Nesse contexto, Agamben compara a contemporaneidade à moda, cujo tempo é inapreensível, razão pela qual "ela pode colocar em relação aquilo que

\footnotetext{
1 O termo usado por Barthes torna-se ainda mais inteligível quando verificamos a versão francesa do texto de Agamben, na qual podemos ler que "le contemporain est l'inactuel" (BARTHES apud AGAMBEN, 2008, p. 8, destaque nosso).
} 
inexoravelmente dividiu, rechamar, reevocar e revitalizar aquilo que tinha até mesmo declarado morto" (AGAMBEN, 2009, p. 68). Ao fazer essa comparação, Agamben evidencia que o contemporâneo, no momento em que fixa o seu olhar nos olhos da sua própria era, percebe que o seu tempo, a despeito de tudo, não apresenta quase nada de novidade. Esse indivíduo é capaz de enxergar na sua própria época todas as outras, tornando-se contemporâneo - em lato sensu — dos homens de todas as eras passadas e vindouras. Para Agamben (2009, p. 44), apenas aquele que experimenta a contemporaneidade consegue perceber que todos os tempos são obscuros. E, segundo ele, “contemporâneo é, justamente, aquele que sabe ver essa obscuridade, que é capaz de escrever mergulhando a pena nas trevas do presente" (AGAMBEN, 2009, p. 63).

Somente o contemporâneo percebe, angustiado, que é impossível separar as luzes e o escuro do seu próprio tempo. Nesse sentido, a contemporaneidade, que para Agamben "não é nenhuma forma de inércia ou passividade, mas [...] uma atividade e uma habilidade particular" (AGAMBEN, 2009, p. 63) de percepção, revela ao contemporâneo que o tempo se constitui como uma experiência completamente paradoxal.

Neste ponto nos lembramos da Alegoria da caverna, de Platão, texto que, a nosso ver, pode ser utilizado para aprimorar a nossa reflexão. Nele, há homens acorrentados, com as suas cabeças imóveis, impossibilitados de uma visão ampla de si mesmos e de tudo ao seu redor. Iludidos pela luz do fogo, eles possuem uma ideia distorcida da realidade. Seguindo a proposição que Sócrates faz a Glauco, se um desses homens se libertasse das correntes e alcançasse o exterior da caverna, além de perceber a existência de uma caverna, ele se depararia comum mundo maior e mais complexo que o espaço que ele conhecia outrora. Além disso, ao contrário dos seus antigos companheiros, esse homem não poderia mais se iludir com as figuras distorcidas que a chama produz no interior da caverna, observandoa também externamente.

O contemporâneo é como esse o homem que vê e vem do lado de fora. Detentor de uma capacidade de percepção singular, ele não se permite seduzir pelas luzes da sua época. Depois de enxergar o mundo externo, iluminado pela 
intensa luz do sol, há algo no interior do seu tempo-caverna que lhe chama mais a atenção do que toda luz, e é justamente a escuridão. Como afirma Agamben, o contemporâneo "percebe o escuro do seu tempo como algo que lhe concerne e não cessa de interpelá-lo, algo que, mais do que toda luz, dirige-se direta e singularmente para ele" (AGAMBEN, 2009, p. 64).

Ainda utilizando a situação hipotética da alegoria platônica como ilustração, o homem talvez retornasse à caverna, angustiado por ver o tempo passar mais rapidamente do lado de fora, ou desiludido com o pôr-do-sol. Aflito pela efemeridade da luz e do novo mundo visto somente por ele, esse homem provavelmente sentiria inveja e ao mesmo tempo pena dos que permaneceram prisioneiros, na caverna. Esses, que não tiveram, como ele, a possibilidade de conhecer o mundo externo, não têm, como ele, a menor percepção da sua cruel condição. O contemporâneo, tal como "o homem que vê e vem do lado de fora”, angustia-se precisamente por conhecer a dureza da condição humana, percebendo-se como eterno "homem da caverna", e porver que a sua existência se constitui, necessariamente, como um jogo entre claridade e escuridão.

O não contemporâneo está perfeitamente integrado ao seu tempo-caverna, razão pela qual se maravilha com o fogo que produz figuras distorcidas. $O$ contemporâneo deseja e ao mesmo tempo não deseja ser como ele; a sua vida é esse paradoxo. Como dissemos inicialmente, Nietzsche exerceu influência sobre o pensamento crítico de Agamben, e um trecho da sua Segunda consideração intempestiva parece ilustrar bem essa experiência paradoxal do indivíduo contemporâneo. Vejamos:

Considera o rebanho que passa a teu lado pastando: ele não sabe o que é ontem e o que é hoje; ele saltita de lá para cá, come, descansa, difere, saltita de novo; e assim de manhã até a noite, dia após dia; ligado de maneira fugaz com seu prazer e desprazer à própria estaca do instante, e, por isto, nem melancólico nem enfadado. Ver isto desgosta duramente o homem porque ele se vangloria de sua humanidade frente ao animal, embora olhe invejoso para a sua felicidade - pois o homem apenas quer isso, viver como o animal, sem melancolia, sem dor; e o quer entretanto em vão; porque não quer como o animal. $\mathrm{O}$ homem pergunta mesmo um dia ao animal: por que não me falas sobre tua felicidade e apenas me observas? O animal quer também responder e falar, isso se deve ao fato de que sempre esquece o que queria dizer, mas também já esqueceu esta 
resposta e silencia: de tal modo que o homem se admira disso (NIETZSCHE, 2003, p. 7).

O não contemporâneo é como um rebanho no pasto. Como o animal, ele não tem noção do tempo e apenas se preocupa em viver um dia após outro. Ele não conhece e sequer suspeita que o mundo é infinitamente maior e mais complexo do que o pasto verdejante com o qual está acostumado, razão pela qual vive de forma prazerosa e encontra contentamento na sua própria rotina - ele é feliz. O contemporâneo angustia-se por saber aquilo que o rebanho não conhece: a sua existência efêmera, a gloriosa miséria do mundo, a majestosa ganância dos homens, as leis sublimes e ao mesmo tempo cruéis da natureza, ou "l'horrible fardeau du temps" - como diria Baudelaire, em de seus poemas mais conhecidos (BAUDELAIRE, 1926, p. 123). O conhecimento de mundo do contemporâneo transcende o verde-esperança do pasto. Ele se angustia e ao mesmo inveja, porque, embora se orgulhe da sua elevada consciência, na verdade quer ser feliz e despreocupado como o rebanho. Isso, contudo, não é possível, pois o contemporâneo não possui algo muito importante: a dádiva do esquecimento.

Para Nietzsche, a felicidade está justamente ligada à habilidade de esquecer. O contemporâneo, quando une pela memória todos os tempos, priva-se da felicidade contínua de que desfrutam aqueles que possuem a capacidade da lembrança. Como nos esclarece Nietzsche, "é possível viver quase sem lembrança, sim, e viver feliz assim, como o mostra o animal; mas é absolutamente impossível viver, em geral, sem esquecimento" (NIETZSCHE, 2003, p. 10). Tal esquecimento, que o filósofo alemão denomina força plástica, é, a nosso ver, um dos principais traços do indivíduo não contemporâneo, que é dotado dessa habilidade de viver quase sem lembrança alguma e de, exatamente por isso, não enxergar a dureza do seu próprio tempo - e de nenhum outro. Nesse contexto, Nietzsche faz a seguinte declaração:

Há homens que possuem tão pouco esta força que, em uma única vivência, em uma única dor, frequentemente mesmo em uma única e sutil injustiça, se esvaem incuravelmente em sangue como que através de um pequenino corte; por outro lado, há homens nos quais os mais terríveis e horripilantes acontecimentos da vida e mesmo os atos de sua própria maldade afetam tão pouco que os levam em meio deles ou logo 
em seguida a um suportável bem-estar e a uma espécie de consciência tranquila (NIETZSCHE, 2003, p. 10).

Nesse sentido, podemos afirmar que o não contemporâneo é um indivíduo cego da memória. Ele facilmente esquece os males proporcionados pelas luzes da sua época e se apaixona por elas, que têm por base a ideia de avanço, progresso, evolução ou revolução. Outra metáfora usada por Nietzsche pode nos ajudar a compreender melhor essa relação que o não contemporâneo estabelece e mantém com as grandes luzes do seu tempo e da sua sociedade. Leiamos com atenção o trecho a seguir:

[...] imagine-se um homem mobilizado e impelido por uma paixão violenta [...] por um grande pensamento - como o seu mundo se transforma para ele! Olhando para trás, ele se sente cego; escutando o que se passa ao seu redor, percebe o estranho como um som surdo e desprovido de significação; o que em geral percebe, ele jamais tinha percebido antes; tão sensivelmente próximo, colorido, ressoante, iluminado, como se ele o aprendesse ao mesmo tempo com todos os sentidos. Todas as suas avaliações se transformaram e se desvalorizaram; tantas coisas ele não está mais em condições de avaliar, porque quase não pode mais senti-las: ele se pergunta se não fora por tanto tempo senão o bobo de palavras e opiniões alheias; ele se espanta que sua memória gire incansavelmente em círculos e esteja fraca e cansada para dar quiçá um único salto para fora deste círculo (NIETZSCHE, 2003, p. 12-13).

A história nos mostra, apresentando-nos as suas faces mais sombrias, o quanto essa atitude é perigosa. Os seguidores de Hitler, perdidamente apaixonados pelos ideais aparentemente elevados do partido nacional-socialista, integraram-se perfeitamente ao seu tempo e às suas pretensões. Por esse motivo, não foram capazes de notar a densa escuridão que se escondia por trás daquela ideia luminosa, que, desde o começo, dava fortes indícios de que o "progresso" prometido não era para todos - algo que somente seria perceptível por um olhar contemporâneo.

Algumas das teses Sobre o conceito de história, de Walter Benjamin — que também exerceu forte influência sobre o pensamento crítico de Agamben —, podem nos ajudar a compreender o contemporâneo agambeniano. Na verdade, podemos enxergar o próprio Benjamin como alguém dotado de profunda contemporaneidade. Em Meia-noite na história, ao analisar as teses do filósofo 
alemão, Manuel-Reyes Mate associou o próprio Benjamin à imagem de um herói ao afirmar que ele "quis fixar os seus olhos na Górgona, [...] figura mítica sem rosto que matava quem ousasse encará-la de frente, para arrancar à história o segredo do mal que estava prestes a abater-se sobre a humanidade" (MATE, 2011, p. 9).

Benjamin para nós também aparece como um herói, mas como um herói trágico-moderno ${ }^{2}$ e contemporâneo. Não se trata, pois, do herói convencional, aquele que se revela capaz de superar as limitações humanas e, muitas vezes como ocorre a exemplo das narrativas mais clássicas - , até mesmo lutar em pé de igualdade com os deuses. Não: Benjamin é, sobretudo, um herói inteiramente humano, alguém que luta e que reúne esforços não para levar os homens do seu tempo a alguma possibilidade de salvação - uma vez que esse herói revela-se incapaz de salvar inclusive a si mesmo - , mas justamente com o objetivo de lhes tornar evidente a impossibilidade de se pensar que os progressos — as luzes do seu tempo - podem conduzi-los a alguma salvação, principalmente quando esse pensamento é alimentado por alguém que, tomando para si o papel do herói convencional, normalmente é chamado de führer, de duce, de salvador da pátria, de mito, entre outros termos. Benjamin encarna a figura de feuermelder, isto é, de alarme de incêndio. E, após o seu aviso final, percebendo que as chamas rapidamente tomam conta das escadas, ele salta do andar mais elevado de um prédio erguido à consciência crítica, enxergando o suicídio como a sua única saída de emergência possível.

As teses de Benjamin se revelam como um posicionamento político em meio a um dos momentos mais tenebrosos da história recente da humanidade. Elas surgem da mente de um filósofo alemão de origem judia, exilado na capital francesa desde 1933, quando o nazismo dominou a Alemanha. Ao escrevê-las, Benjamin não tem em mente alguém perfeitamente integrado ao seu tempo, mas, como explica Mate, "alguém que assume conscientemente a sua experiência de sofrimento e que luta contra as suas causas" (MATE, 2011, p.16-17) - apenas esse

\footnotetext{
2 Isso porque, como o próprio Benjamin (1989, p. 94) afirma, a "modernidade heroica se revela como uma tragédia [...]"
} 
indivíduo seria capaz de compreender o que, para Benjamin, necessita ser compreendido.

A nona tese parte da análise de um quadro de Paul Klee intitulado Angelus novus. Nela, Benjamin introduz a figura do anjo da história, o qual, de acordo com o nosso entendimento, possui muita afinidade com aquilo que, via Agamben, aqui chamamos de contemporâneo. Benjamin descreve o quadro de Klee da seguinte maneira:

\footnotetext{
Nele, está representado um anjo, que parece estar a ponto de afastar-se de algo em que crava o seu olhar. Seus olhos estão arregalados, sua boca está aberta e suas asas estão estiradas. O anjo da história tem de parecer assim. Ele tem seu rosto voltado para o passado. Onde uma cadeia de eventos aparece diante de nós, ele enxerga uma única catástrofe, que sem cessar amontoa escombros sobre escombros e os arremessa a seus pés. Ele bem que gostaria de demorar-se, de despertar os mortos e juntar os destroços. Mas do paraíso sopra uma tempestade que se emaranhou em suas asas e é tão forte que o anjo não pode mais fechá-las. Essa tempestade o impele irresistivelmente para o futuro, para o qual dá as costas, enquanto o amontoado de escombros diante dele cresce até o céu. O que nós chamamos de progresso é essa tempestade (BENJAMIN, 1985, p. 226).
}

Observemos que, embora o seu rosto se volte para o passado, esse anjo fixa os olhos no presente, do qual se aproxima e, ao mesmo tempo, deseja afastamento. Ele se faz contemporâneo quando, por sua habilidade de percepção, enxerga, sozinho, a proximidade da catástrofe que acompanha a tempestade que os não contemporâneos insistem em chamar de progresso. Ele é, como Baudelaire mesmo se definiria, alguém “cujos olhos não veem no passado, na profundidade dos anos nada além do desengano e da amargura, e, à sua frente, senão a tempestade, onde não está contido nada de novo, nem ensinamentos nem dores" (BAUDELAIRE apud BENJAMIN, 1989, p. 144).

O anjo da história não é nostálgico, - embora tenha seu rosto voltado para o passado - , não se ilude com as luzes do presente e nem tampouco é esperançoso em relação ao futuro. Ele é como ocontemporâneo, que percebe que a modernidade, a despeito de todos os seus avanços, repete o mesmo de sempre, não traz em si quase nada de novo e se apoia na ilusão de um progresso que 
invariavelmente exige altos custos sociais, frivolizando e multiplicando o sofrimento do homem, como bem explica Mate (2011, p. 217).

Em Charles Baudelaire: um lírico no auge do capitalismo, Benjamin apresenta alguns traços marcantes da modernidade, entre as quais estão o declínio da memória e o isolamento. Embora não tenha chegado aos tempos atuais, Benjamin na sua época já denunciava algo que podemos perceber sem grande dificuldade nos dias de hoje: a tecnologia gera conforto, o qual causa isolamento (cf. BENJAMIN, 1989, p. 124). Tal isolamento, ao aproximar “da mecanização os seus beneficiários” (BENJAMIN, 1989, p. 124), faz com que os indivíduos vivam de forma automática. Essa mecanização da vida coopera para que ele se integre perfeitamente ao sistema, seja adestrado, viva e aja sem plena consciência de determinados fatos. Esse automatismo, que podemos relacionar ao que Nietzsche chamar de força plástica, faz com que o olhar do não contemporâneo fite somente nas luzes e não observe a obscuridade do seu tempo presente. O isolamento gera, nesses indivíduos, uma eficiente anestesia, graças a qual, não neles, não perdura desespero de qualquer espécie.

Benjamin busca em Baudelaire as figuras fundamentais à compreensão não apenas da poesia moderna, mas do próprio fenômeno da modernidade, e Les fleurs du malé presença marcante nas reflexões do filósofo alemão sobre o tema. Ainda em Charles Baudelaire: um lírico no auge do capitalismo, Benjamin apresenta algumas metáforas, associando-as à figura do poeta francês. Algumas delas, para nós especialmente a do flâneur e a do trapeiro, podem ser muito úteis para pensarmos em Baudelaire como artista contemporâneo e, por extensão, em uma arte literária que dialogue com aquilo que Agamben chama de contemporaneidade.

A figura do flâneur, que, como Mate explica, era "um passeador que povoava as grandes cidades europeias do século XIX, nas quais irrompeu a técnica” (MATE, 2011, p. 37), tem semelhança com o indivíduo contemporâneo à medida que se propõe a observar o intenso movimento nas cidades e os grandes inventos do seu tempo, como vitrines de passarelas modernas, feitas com materiais sofisticados para a época, como o ferro e o vidro.

O trapeiro, por sua vez, é aquele recolhe dejetos, que reúne aquilo que é 
descartado pela sociedade. O principal ponto a se observar em relação a essa figura é a impossibilidade de se compor uma obra completa por meio do tipo de material que ele recolhe. Como explicaria Mate, "qualquer intento de construir uma obra acabada, cerrando os olhos à realidade dos dejetos, será falsa" (MATE, 2011, p. 39). E nesse sentido podemos aqui chegar ao que talvez seja a primeira marca de uma literatura que vá ao encontro da contemporaneidade como fenômeno singular de percepção.

Para compreender essa relação, basta observar o fato de que Theodor Adorno, coetâneo de Benjamin, no século XX já apontava o caráter fragmentário como um dos principais traços da obra de arte moderna, que "salienta o momento outrora oculto do fabricado, do produzido" (ADORNO, 1970, p. 39), mostrando-se virtualmente como work in progress, isto é, uma obra incompleta, fragmentada, em constante produção - o exato oposto da obra de arte tradicional. Nesse sentido, entendemos que uma literatura do contemporâneo se faria inacabada e fragmentária para, assim como a arte observada por Adorno, em vez de achar-se segura em si mesma, ter maior segurança "na 'consciência dos sofrimentos', na dor ilimitada que aflige os homens" (ADORNO, 1974, p. 22).

Para nós, não há nada que aflija mais o contemporâneo do que a efemeridade da sua existência, do que a sua impotência diante da crueldade do tempo e da morte como fato. Por essa razão, aliada à fragmentação de que falamos, a efemeridade que Adorno também vê presente na obra de arte moderna - seria outra marca de uma literatura do contemporâneo. O autor de A filosofia da nova música explica que é pela sua duração que "a obra protesta contra a morte; a eternidade a curto prazo das obras é a alegoria de uma eternidade não aparente. [...] O esforço por criar obrasprimas duradouras está votado à ruína” (ADORNO, 1970, p. 40). Acreditamos que, tal como a obra de arte observada por Adorno, uma literatura do contemporâneo, tomando para si o sentimento trágico da vida, desprezaria a glória de um brilho eterno e iluminaria os céus somente como fogo de artifício - apparition (ADORNO, 1970, p. 98) - , por um breve instante.

Como o contemporâneo é aquele se aproxima e ao mesmo tempo se mantém distante do seu próprio tempo, há outro traço da obra de arte moderna 
apresentado por Adorno que parece conformar-se à ideia de uma literatura do contemporâneo: o seu aparente isolamento social. A arte moderna parece distanciar-se do público, e isso diz muito a respeito da própria condição do indivíduo moderno, tornando evidente a fragilidade das suas relações.

Também desejamos aqui estabelecer como pressuposto - e como pressuposto principal - a ideia de uma literatura do contemporâneo que, de modo semelhante à arte observada por Adorno, desconcerta, choca, por vezes é desagradável e que, sobretudo, toma "sobre si todas as trevas e as culpas do mundo" (ADORNO, 1974, p. 107). A fim de evidenciar a obscuridade da realidade do contemporâneo, rejeitando o papel redentor da consolação, essa forma de arte literária evidenciaria a angústia e denunciaria a ausência de beleza percebida pelo contemporâneo. Seria, pois, uma literatura sem pretensão de ser agradável ou confortável - e, por isso, dificilmente digerida por alguém cujos olhos não experimentem da contemporaneidade.

O contemporâneo, como explica Agamben, "dividindo e interpolando o tempo, está à altura de transformá-lo” (AGAMBEN, 2009, p. 72). Por essa razão, entendemos que a literatura como manifestação artística legitimamente contemporânea também se colocaria à altura de realizar, no mundo, algum tipo intervenção. Contudo, longe de levantarmos a bandeira de uma literatura da utilidade, para nós essa forma de literatura trabalharia o desespero do homem ao olhar para o tempo com criticidade, alimentando a consciência crítica do sujeito contemporâneo, organizando o seu desespero e convidando-o ao questionamento, à reflexão - algo que se revela especialmente necessário aos tempos de autoverdade que experimentamos nos dias de hoje.

\section{Referências}

ADORNO, Theodor W. Filosofia da nova música. Tradução de Magda França. São Paulo: Perspectiva, 1974 . 
AGAMBEN, Giorgio. Qu'est-ce que le contemporain?. Tradução de Maxime Rovere. Paris: Payot \& Rivages, 2008.

. O que é o contemporâneo? e outros ensaios. Tradução de Vinícius Nicastro. Chapecó: Argos, 2009.

BAUDELAIRE, Charles. Les fleurs du mal. 2 ed. Augmentée de trente-cinq poèmes nouveaux et ornée d'un portrait de l'auteur dessiné et gravé par Bracquemond. Paris: Poulet-Malassis et Broise, 1861.

BENJAMIN, Walter. Obras escolhidas III. Tradução de José Carlos Martins Barbosa e Hemerson Alves Baptista. São Paulo: Editora Brasiliense, 1989. 3 v. V. 3: Charles Baudelaire: um lírico no auge do capitalismo.

Sobre o conceito de história. Obras escolhidas I. 1 ed. Tradução de Sergio Paulo Rouanet. São Paulo: Brasiliense, 1985. 3 v. V. 1: Magia e técnica, arte e política — ensaios sobre literatura e história da cultura.

MATE, Manuel-Reyes. Meia-noite na história. Comentários às teses de Walter Benjamin sobre o conceito de história. Tradução de Nélio Schneider. São Leopoldo: Editora Unisinos, 2011.

NIETZSCHE, Friedrich. Segunda consideração intempestiva: da utilidade e desvantagem da história para a vida. Tradução de Marco Antônio Casanova. Rio de Janeiro: Relume Dumará, 2003.

PESSOA, Fernando. O guardador de rebanhos e outros poemas. São Paulo: Cultrix, 1993.

PLATÃO. A alegoria da caverna: A República, 514a-517e. Tradução de Lucy Magalhães. In: MARCONDES, Danilo (Org.). Textos Básicos de Filosofia: dos Présocráticos a Wittgenstein. 2 ed. Rio de Janeiro: Jorge Zahar Editor, 2000.

\footnotetext{
* Doutorando e Mestre em Teoria da Literatura e Literatura Comparada pela Universidade do Estado do Rio de Janeiro.
} 